\title{
IDENTIFIKASI PENULIS MELALUI POLA TULISAN TANGAN MENGGUNAKAN ALGORITMA SUPPORT VECTOR MACHINE
}

\author{
Teny Handhayani \\ Program Studi Teknik Informatika, Fakultas Teknologi Informasi, Universitas Tarumanagara \\ tenyh@fti.untar.ac.id
}

\begin{abstract}
ABSTRAK
Tulisan tangan merupakan ciri biometrik karena setiap orang memiliki pola tulisan tangan yang unik. Keunikan tersebut dapat dimanfaatkan sebagai identitasbiometrik. Pada penelitian ini, peneliti menggunakan algoritma Support Vector Machine beserta fitur GLCM dan Histogram untuk melakukan pengenalan pola tulisan tangan. Pengenalan pola tulisan tangan tersebut digunakan untuk mengidentifkasi penulisnya. Eksperimen dilakukan dengan menggunakan data citra tulisan tangan dari 47 respoden. Pembagian data latih dan data uji secara acak dengan perbandingan 70\%:30\%. Pada eskperimen pertama, identifikasi penulis melalui pola tulisan tangan dilakukan dengan membandingkan pola tulisan dari setiap responden secara berpasangan. Support Vector Machine kernel linear berhasil mengidentifikasi penulis dengan rata-rata akurasi 99\%. Pada eksperimen ke dua, identifikasi penulis dilakukan menggunkan keseluruhan data. Pada eksperimen ini, Support Vector Machine kernel linear menghasilkan rata-rata akurasi $93.5 \%$.
\end{abstract}

Kata kunci: pengenalan tulisan tangan, SVM, GLCM, Histogram

\section{PENDAHULUAN}

Tulisan tangan setiap orang memiliki bentuk dan pola yang berbeda antara satu orang dengan orang lainnya.Hal ini dapat dijadikan sebagai ciri biometrik yang bermanfaat untuk berbagai keperluan, seperti sistem keamanan pada perangkat digital dan pelacakan identitas seseorang.Ciri biometrik yang digunakan dalam sistem sekuriti memiliki tingkat keamanan yang tinggi karena bersifat unik untuk setiap orang. Sidik jari dan retina mata merupakan ciri biometrik yang banyak digunakan untuk membangun aplikasi sekuriti.Sistem sekuriti berbasis biometric yang menggunakan berbagai jenis data seperti sidik jari, retina, garis tangan dan wajah membutuhkan perangkat keras khusus yang mahal.Tulisan tangan juga memiliki pola yang unik sehingga memungkinkan digunakan untuk membangun sistem sekuriti digital yang lebih murah karena tidak membutuhkan peralatan khusus.

Pengenalan pola tulisan tangan merupakan bagian dari bidang penelitian pengenalan pola.Pengenalan pola tulisan tangan dapat dilakukan secara online dan offline.Pengenalan tulisan tangan secara online (online hand writing recognition)merupakan teknik pengenalan pola tulisan tangan dengan menggunakan peralatan mobile.Sistem pengenalan tulisan tangan secara online mengharuskan pengguna menuliskan secara langsung sejumlah huruf dan/atau angka pada perangkat mobile.Pengenalan tulisan tangan secara offline (offline hand writing recognition) menggunakan data citra hasil pemindaian tulisan tangan.

Penelitian ini merupakan pengenalan pola tulisan tangan secara offlinesebagai model untuk mengidentifikasi penulisnya.Penelitian ini merupakan bagian dari projek penelitian untuk membangun aplikasi sekuriti menggunakan biometriktulisan tangan.Pada penelitian ini, peneliti mengajukan metode Support Vector Machine (SVM) untuk melakukan pengenalan pola tulisan tangan dengan fitur Gray Level Co-occurrence Matrix (GLCM), dan Histogram.Support Vector Machine dan Gray Level Co-occurrence Matrixtelah berhasil digunakan dalam pengenalan tulisan tangan yang dilakukan oleh Hanusiak et al (Hanusiak et al, 2015). Hanusiak et al menggunakan data tulisan tangan dengan membuang spasi antar huruf dan spasi antar baris, sehingga data yang tersisa merupakan bentuk dari karakter yang dituliskan oleh responden(Hanusiak et al, 2015).Pada penelitian ini, penulis menggunakan data tulisan tangan tanpa membuang spasi antar huruf dan spasi antar baris karena spasi pada tulisan tangan 
merupakan fitur yang penting dan dapat digunakan sebagai informasi untuk pengenalan polsa tulisan tangan.Penelitian ini bertujuan untuk membangun proto-type sistem pengenalan tulisan tangan secara offline menggunakan data citra pindai (scanned documents) untuk mengidentifikasi penulis.

\section{STUDI LITERATUR}

Penelitian pengenalan tulisan tangan telah dilakukan dengan berbabagi teknik.Mohammed dan Shamsuddin menggunakan invariant discretization untuk mengenali pola tulisan tangan pada pasangan kembar.Penelitian tersebut menujukkan bahwa pasangan kembar memiliki pola tulisan tangan yang berbeda (Mohammed dan Shamsuddin, 2012).Discrete Wavelet Transform juga terlah berhasil digunakan untuk mengektraksi fitur pergerakan pena dan pergerakan sudut untuk mengenali pola tulisan tangan (Fahmy, 2010). Bertolini et almenggunakan local binary patterns dan local phase quantization untuk mengekstraski ciri tektur pada tulisan tangan (Bertolini et al, 2013).Pengenalan tulisan tangan yang dilakukan oleh Abushariah et al menggunakan global fitur dan Neural Network menghasilkan akurasi 53\% - 79\%.Pernelitian tersebut juga menghasilkan akurasi 81\% dengan menggunakan algoritma KNN (Abushariah et al, 2012).

Beberapa penelitian telah dilakukan untuk mengdentifikasi penulis melalui pola tulisan tangan. Xiong et al (2015) menggunakan SIFT dan contour-directional feature (CDF) untuk mengenali penulis melalui pola tulisan tangan. Hannad et al (2015) menggunakan tekstur deskriptor histogram Local Binary Pattern (LBP), Local Ternary Pattern (LTP) dan Local Phase Quantization (LPQ) sebagai metode ekstraksi fitur tulisan tangan untuk mengidentifkasi penulis. Metode yang diajukan oleh Hannad et al menghasilkan akurasi 92\% - 95\% (Hannad et al, 2015).DeepWriterID merupakan metode yang digunakan oleh Yang et al (2016) untuk mengidentifikasi penulis menggunakan teks tulisan China dan tulisan latinpada teks berbahasa Inggris. Yang et al (2016) menggunakan deep convolutional neural network (CNN). Pada penelitian tersebut, pengenalan penulis pada teks tulisan China menghasilkan akurasi $95.72 \%$, sedangkan hasil pengenalan pada teks tulisan berbahasa Inggris mencapai akurasi $98.51 \%$ (Yang et al, 2016).

\section{METODE PENELITIAN}

\section{Algoritma}

Gray Level Co-occurrence Matrix (GLCM) merupakan teknik ekstraksi ciri berbasis tekstur pada data citra.Teknik ini diperkenalkan oleh Haralick et al pada tahun 1973 (Haralick et al, 1973).Teknik GLCM mengekstraksi ciri contrast, correlation, energy dan homogeneity yang dihitung menggunakan formula (1) - (4) (Haralick et al, 1973).Nilai $P(i, j)$ merupakan nilai piksel pada citra.GLCM banyak digunakan sebagai teknik ekstraksi ciri pada data citra.Handhayani menggunakan teknik GLCM untuk melakukan pengenalan motif Batik Lasem (Handhayani, 2016).

$$
\begin{aligned}
& \text { Energy }=\sum_{i=1}^{N} \sum_{j=1}^{N} P(i, j)^{2} \\
& \text { Homogeneity }=\sum_{i=1}^{N} \sum_{j=1}^{N} \frac{P(i, j)}{|i-j|}
\end{aligned}
$$


Contrast $=\sum_{i=1}^{N} \sum_{j=1}^{N}(i-j)^{2} P(i, j)$

Correlation $=\frac{\left(i-\mu_{i}\right)\left(j-\mu_{j}\right) P(i, j)}{\sigma_{i} \sigma_{j}}$

Histogram of oriented gradients (HOG) merupakan metode ekstraksi ciri pada citra grayscale.Metode tertesbut menghasilkan nilai vektor yang merupakan ciri bentuk lokal pada citra (Dalal dan Triggs, 2005).

Support Vector Machine dikembangkan oleh Vapnik sebagai algoritma klasifikasi (Cristianini \& Taylor, 2000). Data input $x$ dipetakan ke pada sebuah dimensi tingkat tinggi menggunakan pemetaan nonlinear. Algoritma Support Vector Machine (SVM) menghitung bidang pemisah (hyperplane) yang dapat memisahkan kelompok data dengan kesalahan minimal (Cristianini \& Taylor, 2000).Pada awalnya SVM dibuat untuk mengklasifikasi data menjadi dua kelas, misalnya kelas -1 dan kelas +1 .Gambar 1(a) menunjukkan beberapa kemungkinanhyperplane yang dapat digunakan untuk memisahkan dua kelas.SVM bekerja dengan mencari optimal hyperplane yaitu bidang pemisah yang membentuk maksimal margin sehingga dapat memisahkan dua kelas berbeda dengan meminimalkan error.Gambar 1(b) menunjukkan optimal hyperplane pada linear separable data.Gambar 1(c) menunjukkan hyperplane untuk nonlinear separable data yang dapat dikerjakan dengan menggunakan kernel method.Menurut Cristianini dan Taylor (2000), hyperplane dapat dihitung dengan formula (5).

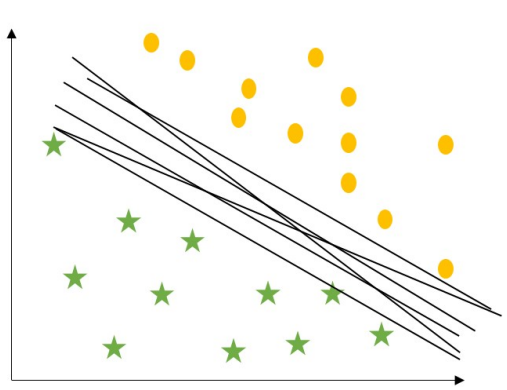

(a)

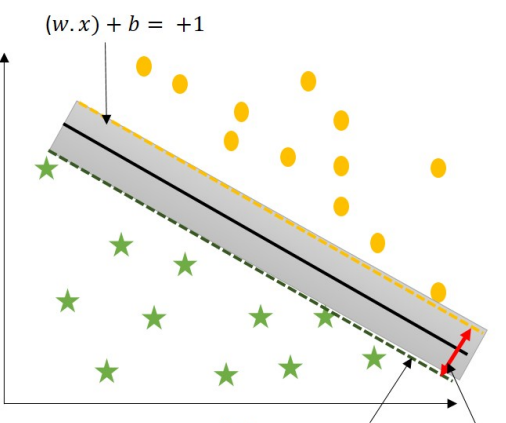

(b) (w. $x)+b=-1$

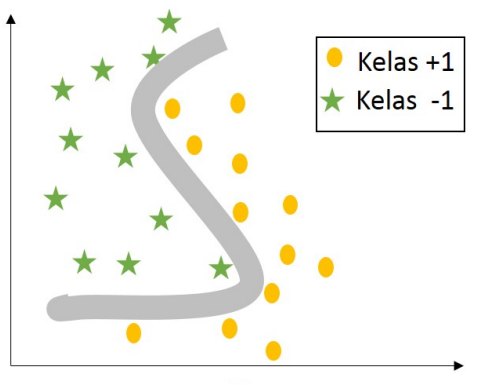

(c)

Maksimal margin

Gambar 1 Hyperplane pada SVM

$\left\{\begin{array}{l}\text { w. } x+b \geq+1, \text { jika } y_{k}=+1 \\ \text { w. } x+b \leq-1, \text { jika } y_{k}=-1\end{array}\right.$

SVM juga telah dikembangkan untuk klasifikasi multi kelas.Beberapa teknik klasifikasi multi kelas dengan SVM yaitu One-Against-All, One-Against-One dan Directed Acyclic Graph Support Vector Machine (Hsu dan Lin, 2002).SVM telah berhasil digunakan untuk penelitian yang mengunakan data citra.Karargyris et al menggunakan Support Vector Machine untuk membangun DERMA/care sistem identifikasi penyakit kanker kulit (Karargyris, 2012).

Gambar 2 menunjukkan metode penelitian dan algoritma yang digunakan. Ekstraksi ciri merupakan proses penghitungan ciri tekstur menggunakan algoritma GLCM dan Histogram. Fitur GLCM contrast, correlation, energy dan homogeneitydihitung pada sudut $0^{\circ}, 45^{\circ}, 90^{\circ}$ dan $135^{\circ}$. Deskriptor fitur histogram yang digunakan yaitu nilai minimum, maksimum, mean dan median.Nilai fitur yang dihasilkan memiliki rentang nilai yang berbeda sehingga perlu dilakukan 
proses standarisasi. Proses standarisasi nilai fitur dilakukan menggunakan formula (6) (Mirkin, 2005). Setelah ekstraksi ciri, tahap berikutnya yaitu pengenalan tulisan tangan menggunakan algoritma Support Vector Machine.

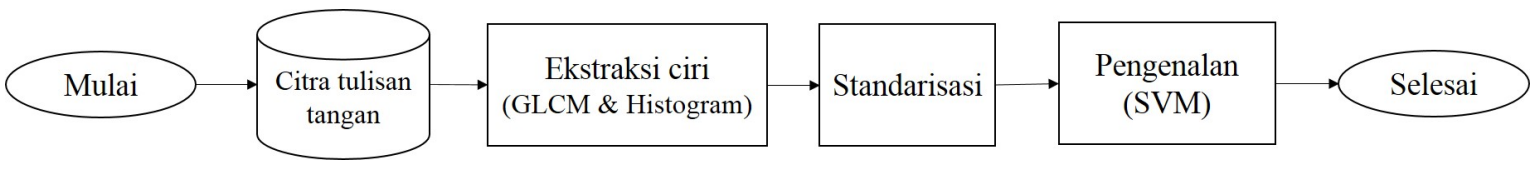

Gambar 2 Metode penelitian

$y_{i v}=\frac{x_{i v}-a_{v}}{b_{v}}$

$y_{i v}=$ nilai fitur $v$ dari instance ke $i$

$a_{v}=$ mean fitur $v$

$b_{v}=$ standar deviasi fiturv

\section{HASIL DAN PEMBAHASAN}

Data

Penelitian ini menggunakan data citra tulisan tangan yang peroleh dari responden yang berusia 20-40 tahun. Setiap responden menuliskan kalimat yang sama sebanyak 10 kali pada selembar kertas A4. Data dipindai menggunakan mesin HP 1515 dan disimpan dalam format .jpg.Citra hasil pemindaian merupakan citra RGB yang selanjutnya ditransformasi menjadi citra grayscale.Gambar 3 merupakan contoh data citra tulisan tangan yang digunakan pada penelitian ini.Pada penelitian ini terdapat 47 responden yang berpartisipasi menberikan data tulisan tangan. Responden menjadi kelas target, sehingga dari data diperoleh 47 kelas. Gambar 3 menunjukkan sampel dua citra tulisan tangan untuk setiap kelas.Ekstraksi fitur dilakukan dengan menggunakan GLCM dan Histogram. Nilai fitur yang digunakan untuk eskperimen merupakan nilai fitur setelah proses standarisasi. Gambar 4 menunjukkan contoh nilai fitur setelah proses standarisasi.

\begin{tabular}{|c|c|c|c|}
\hline $\begin{array}{l}\text { The freld or machine learning is concerned } \\
\text { with the question of how to consfruct } \\
\text { computer programs fhat aufomaticallit } \\
\text { improve with experience }\end{array}$ & $\begin{array}{l}\text { The field or machine learning is concerned } \\
\text { with the question of how to construct } \\
\text { computer programs fhat automatically } \\
\text { improve with experience }\end{array}$ & Responden 1 & Kelas 1 \\
\hline $\begin{array}{l}\text { The field of machine fearning is concerned } \\
\text { With the question of how to construct } \\
\text { Camputer Programs that automatically } \\
\text { Improve with experience }\end{array}$ & $\begin{array}{l}\text { The field of machine learning is concerned } \\
\text { with the question of how to construct } \\
\text { computec programs that automatically } \\
\text { Improvi with experience }\end{array}$ & Responden 2 & Kelas 2 \\
\hline $\begin{array}{l}\text { The field of machine learning is concermed } \\
\text { With the question of how to construct } \\
\text { computer programs that automatically } \\
\text { Improve with experience. }\end{array}$ & $\begin{array}{l}\text { The field of machine learning is concerned } \\
\text { With the question of how to construct } \\
\text { computer programs that automatically- } \\
\text { Improve with experience. }\end{array}$ & Responden 3 & Kelas 3 \\
\hline $\begin{array}{l}\text { The field of machine learning is concerned } \\
\text { with the question of how to construct } \\
\text { computer programs that cutomatically } \\
\text { lappove with experience }\end{array}$ & $\begin{array}{l}\text { The ficld of machine learning is concerned } \\
\text { with the questrom of how to construct } \\
\text { Computer programs that automatically } \\
\text { Improve with experence }\end{array}$ & Responden 4 & Kelas 4 \\
\hline
\end{tabular}

Gambar 3 Citra tulisan tangan 
Vol. 1, No. 1, April 2017: hlm 210-217

\begin{tabular}{|c|c|c|c|c|c|c|c|c|c|c|}
\hline 2 & A & B & 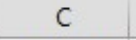 & D & E & r & G & $\mathrm{H}$ & & \\
\hline 1 & -1.34311 & 241 & 392221 & .540688 & 39 & .66744 & -2.95836 & .36581 & 0.769511 & -0.59408 \\
\hline 2 & .34311 & .92275 & 478257 & 236 & 46 & & & & & \\
\hline 3 & 4311 & .05161 & 265686 & 552 & 0.26296 & .68676 & -3.23088 & & 0.314316 & \\
\hline 4 & & & 506134 & & & & & & & \\
\hline 5 & & & & & & & & & & \\
\hline 6 & .34311 & 3941 & 957607 & 014875 & -0.92 & & & & & \\
\hline 7 & L.34311 & 0.80146 & 559 & 676 & & & & & & \\
\hline 8 & & & & & & & & & & \\
\hline 9 & & & & & & & & & & \\
\hline & & & & & & & & & & \\
\hline & 1.21 & 0.558228 & & & & & & & & \\
\hline 2 & 28011 & . 097977 & 0.016461 & 52714 & 55 & -0.10 & 0.2638 & 02024 & 0.4 & \\
\hline 3 & 3812 & 566 & .1590 & & & & & & & \\
\hline & & & & & & & & & & \\
\hline & & 0.744115 & & & & & & & & \\
\hline 6 & -0.31792 & 36347 & -0.05837 & 0.67617 & 0.057638 & 0.015202 & 0.341799 & -0.49121 & 1.520658 & 22 \\
\hline 7 & 8878 & 123 & & 03 & & & & & & \\
\hline 8 & & & & & & & 0.47 & & & \\
\hline 8 & & & & & & & & & & \\
\hline 0 & & & & & -0.43938 & 0.228166 & 0.67533 & 0.160082 & 0.436175 & 0.172195 \\
\hline
\end{tabular}

Gambar 4 Contoh nilai fitur setelah standarisasi

\section{Hasil Eksperimen dan Pembahasan}

Pada penelitian ini, sistem dikembangkan dengan bahasa pemrograman Python 2.7, modul OpenCV 3.0, dan scikit-learn.Eksperimen dilakukan melalui 2 tahapan.Tahap pertama yaitu ekstraksi fitur.Semua data citra terlebih dahulu dijadikan citra grayscale sebelum proses ekstraksi fitur. Hasil dari ekstraksi fitur GLCM contrast, correlation, energy dan homogeneitypada sudut $0^{0}, 45^{\circ}, 90^{\circ}$ dan $135^{\circ}$ diperoleh 16 fitur.Hasil ekstraksi fitur histogram dengan deskriptor nilai minimum, maksimum, mean dan median diperoleh 4 fitur.Eksperimen menggunakan 20 fitur dan 47 kelas.Nilai fitur tersebut selanjutnya dilakukan standarisasi agar tidak terdapat perbedaan nilai yang sangat besar antara fitur satu dengan lainnya.

Eksperimen dilakukan dengan membagi data latih dan data uji sebanyak 70\%:30\%. Data latih dan data uji dipilih secara acak.Pada saat eksperimen, peneliti menggunakan 3 algoritma untuk melakukan pengenalan. Decision Tree dan Gaussian Naïve Bayes digunakan sebagai pembanding kinerja Support Vector Machine. Tabel 1 menunjukkan hasil eksperimen. Pada Tabel 1, terdapat 3 skenario eksperimen menggunakan kombinasi fitur GLCM dan Histogram. Eksperimen dilakukan dengan menggunakan pasangan data dari dua kelas yang berbeda.Hal ini dilakukan untuk mengidentifikasi penulis dengan membandingkan tulisan dari satu responden dengan responden lainnya.Setiap skenario eksperimen dilakukan proses pemilihan data latih dan data uji secara acak serta pengenalan sebanyak 10 kali. Setiap eksperimen dihitung nilai akurasinya.Perbandingan kinerja algoritma SVM, Decision Tree dan Gaussian Naïve Bayes dilakukan dengan menggunakan data latih dan data uji yang sama. Nilai rata-rata akurasi dijadikan sebagai indikator tingkat keberhasilan.Semakin tinggi nilai akurasi berarti tulisan tangan responden satu dengan lainnya dapat dikenali dengan baik oleh sistem.Hal ini berarti sistem berhasil membedakan pola tulisan tangan dari responden yang berbeda. 
Tabel 1 Hasil eksperimenmenggunakan data pasangan responden

\begin{tabular}{lrrll}
\hline \multirow{2}{*}{ Fitur } & \multicolumn{4}{c}{ Akurasi \pm Std. Deviasi } \\
\cline { 2 - 5 } & SVM RBF & SVM Linear & Decision Tree & Gaussian Naïve Bayes \\
\hline GLCM & $98.9 \% \pm 0.039$ & $99.5 \% \pm 0.022$ & $95.0 \% \pm 0.056$ & $98.0 \% \pm 0.043$ \\
\hline Histogram & $96.8 \% \pm 0.075$ & $97.1 \% \pm 0.071$ & $93.9 \% \pm 0.085$ & $96.2 \% \pm 0.071$ \\
\hline GLCM+Histogram & $99.5 \% \pm 0.022$ & $99.7 \% \pm 0.014$ & $95.3 \% \pm 0.051$ & $98.6 \% \pm 0.033$ \\
\hline
\end{tabular}

Pada penelitian ini peneliti menggunakan Support Vector Machine dapat bekerja untuk mengklasifikasi linear separable data dan non-linear separable data.Penulis juga menggunakan GLCM dan Histogram karena dalam penelitian ini peneliti memfokuskan studi kasus untuk mengenali tulisan tangan berdasarkan tekstur citra grayscale.Peneliti menggunakan SVM dengan kernel linear dan RBF.

Eksperimen menggunakan fitur GLCM, Histogram dan gabungan GLCM dan Histogram menghasilkan nilai akurasi mencapai 99\% dengan menggunakan SVM kernel linear maupun SVM RBF kernel. Hal ini dapat dikatakan bahwa fitur GLCM dan Histogram dapat digunakan untuk mengidentifikasi penulis melalui pola tulisan tangannya.Kombinasi fitur GLCM dan histogram juga menunjukkan hasil akurasi tertinggi jika dibandingkan hanya menggunakan salah satu fitur.Hasil eksperimen pada ketiga skenario juga menunjukkan nilai error yang kecil.

Penulis juga melakukan eksperimen dengan menggunakan semua data dari keseluruhan kelas.Tabel 2 menunjukkan hasil eksperimen menggunakan semua data dari 47 kelas.Eksperimen ini dilakukan sebanyak 50 kali pemilihan data latih dan data uji dengan perbandingan 70\%:30\%. Pada eksperimen ini, sistem melakukan pengenalan pada 47 kelas secara bersamaan.Hasil eskperimen menunjukkan bahwa SVM dengan kernel linear memperoleh akurasi $93.6 \%$ pada saat mengidentifikasi penulis menggunakan gabungan fitur GLCM dan Histogram.

Tabel 2 Hasil eksperimen menggunakan data dari seluruh kelas

\begin{tabular}{lrrrl}
\hline \multirow{2}{*}{ Fitur } & \multicolumn{4}{c}{ Akurasi \pm Std. Deviasi } \\
\cline { 2 - 5 } & SVM RBF & SVM Linear & Decision Tree & Gaussian Naïve Bayes \\
\hline GLCM & $77.0 \% \pm 0.112$ & $88.1 \% \pm 0.127$ & $67.2 \% \pm 0.102$ & $74.1 \% \pm 0.109$ \\
\hline Histogram & $55.6 \% \pm 0.085$ & $57.8 \% \pm .0879$ & $48.5 \% \pm 0.078$ & $57.4 \% \pm 0.087$ \\
\hline GLCM+Histogram & $88.1 \% \pm 0.125$ & $93.6 \% \pm 0.133$ & $69.9 \% \pm 0.103$ & $81.7 \% \pm 0.118$ \\
\hline
\end{tabular}

Eksperimen mengidentifikasi penulis melalui pola tulisan tangan menggunakan fitur GLCM, histogram dan metode klasifikasi SVM menghasilkan nilai akurasi lebih dari $90 \%$.Hal ini membuktikan bahwa tulisan tangan setiap orang memiliki bentuk dan pola yang unik sehingga tulisan tangan dapat dimanfaatkan untuk identifikasi biometrik.Sistem identifikasi biometrik menggunakan tulisan tangan tidak membutuhkan peralatan khusus yang mahal. Berdasarkan hasil eksperimen pada Tabel 1 dan Tabel 2, Support Vector Machine menggunakan kernel linear maupun kernel RBF menghasilkan nilai akurasi tertinggi dibandingkan dengan akurasi Decision Tree dan Gaussian Naïve Bayes. SVM dengan kernel linear memiliki performa akurasi lebih tinggi dari SVM dengan kernel RBF. 
Hasil eksperimen juga menunjukkan bahwa performa gabungan fitur GLCM dan Histogram menghasilkan rata-rata nilai akurasi yang lebih tinggi dibandingkan dengan performa masingmasing fitur secara terpisah.Hal ini berlaku pada algoritma SVM, Decision Tree dan Gaussian Naïve Bayes.Pada setiap bagian eksperimen, nilai standar deviasi dari akurasi <0.2.Hal ini menunjukkan bahwa akuasi yang diperoleh dari setiap eksperimen tidak memiliki penyimpangan yang besar.

\section{KESIMPULAN DAN SARAN}

Tulisan tangan setiap orang memiliki bentuk dan karakter yang berbeda sehingga dapat digunakan sebagai identifikasi biometrik.Penelitian ini merupakan pengenalan pola tulisan tangan untuk mengidentifikasi penulisnya.Peneliti menggunakan fitur GLCM dan Histogram untuk mengidentfikasi penulis melalui data citra tulisan tangan.Data yang digunakan yiatu citra tulisan tangan dari 47 responden yang dikelompokkan menjadi 47 kelas.Pada eskperimen pertama, peneliti menggunakan data dari pasangan responden.SVM linear kernel dengan fitur GLCM dan Histogram berhasil menunjukkan kinerja dengan rata-rata akurasi 99\%.Pada eksperimen ke dua, peneliti melakukan identifikasi penulis menggunakan data dari semua kelas.SVM linear kernel beserta gabungan fitur GLCM dan Histogram menghasilkan rata-rata akursi 93.6\%.Hasil penelitian menunjukkan bahwa tulisan tangan memiliki ciri yang unik dan dapat digunakan untuk mengidentifikasi seseorang.Penelitian ini selanjutnyaakan dikembangkan untuk membangun aplikasi sistem keamanan digital menggunakan ciri biometrik tulisan tangan.

\section{Ucapan Terima Kasih (Acknowledgement)}

Penulis mengucapkan terimakasih kepada seluruh responden yang berpartisipasi untuk memberikan data tulisan tangan.

\section{REFERENSI}

Abushariah, A., Gunawan, T., Chebil, J., \& Abushariah, M. (2012). Automatic Person Identification System Using Handwritten Signatures. International Conference on Computer and Communication Engineering (ICCCE 2012) (pp. 560-565). Kuala Lumpur: IEEE.

Bertolini, D., Oliveira, L., Justino, E., \& Sabourin, R. (2013). Texture-based descriptors for writer identification and verification. Journal Expert Systems with Applications, 40, 2069 2080.

Cristianini, N., \& Taylor, J. (2000). An Introduction to Support Vector Machines and Other Kernel-Based Learning Methods. Cambrodge: The Press Syndicate of the University of Cambridge.

Dalal, N., \& Triggs, B. (2005). Histograms of Oriented Gradients for Human Detection. IEEE Computer Society Conference on Computer Vision and Pattern Recognition, 1, 886-893.

Fahmy, M. M. (2010). Online handwritten signature verification system based on DWT features extraction and neural network classification. Engineering Journal, 1(1), 59-70. doi:10.1016/j.asej.2010.09.007

Handhayani, T. (2016). Batik Lasem Images Classification Using Voting Feature Intervals 5 and Statistical Features Selection Approach . International Seminar on Intelligent Technology and Its Application (pp. 13-16). Senggigi, Lombok: IEEE.

Hannad, Y., Siddiqi, I., \& Kettani, M. E. (2015). Writer Identification Using Texture Descriptors of Handwritten Fragments. Expert Systems With Applications. 
Hanusiak, R. K., Oliveira, L. S., Justino, E., \& Sabourin, R. (2015, September). Writer verification using texture-based features. International Journal on Document Analysis and Recognition, 15(3), 213-226.

Haralick, R. M., Shanmugam, K., \& Dinstein, I. (1973). Texture Features for Images Classification. IEEE Transaction on System, MAN and Cybernetics, Vol. SMC-3, 610-621.

Hsu, C.-W., \& Lin, C.-J. (2002). A Comparison of Methods for Multiclass Support Vector Machines. IEEE, 13(2), 415-425.

Karargyris, A., Karargyris, O., \& Pantelopoulos, A. (2012). DERMA/care: An Advanced ImageProcessing Mobile Application for Monitoring Skin Cancer. The 24th International Converence on Tools with Artificial Intelligence (pp. 1-7). IEEE.

Mirkin, B. (2005). Clustering for Data Mining: A Data Recovery Approach. London: Chapman and Hall/CRC.

Mohammed, B., \& Shamsuddin, S. (2012). Improvement in twins handwriting identification with invariants discretization. EURASIP Journal on Advances in Signal Processing, 48, 112.

Xiong, Y.-J., Wen, Y., Wang, P. S., \& Lu, Y. (2015). Text-independent Writer Identification Using SIFT Descriptor and Contour-directional Feature. 13th International Conference on Document Analysis and Recognition (ICDAR), (pp. 91-95).

Yang, W., Jin, L., \& Liu, M. (2016). DeepWriterID: An End-to-end Online Text-independent Writer Identification System. IEEE Intelligent Systems, 31(2), 45-53. 